\title{
Proposta de redução do lead time de uma linha de pintura automotiva
}

Lead time reduction proposal for an automotive painting line

\section{Propuesta de reducción del lead time de una línea de pintura automotora}

\author{
EDUARDO JOSÉ SILVA \\ Graduação em Engenharia de Produção \\ Carla Roberta Pereira \\ Doutorado em Engenharia de Produção \\ Professora da Universidade Federal de Santa Catarina - UFSC \\ DANielle Bond \\ Doutorado em Engenharia e Ciência dos Materiais \\ Professor Adjunto da Universidade do Estado de Santa Catarina - UDESC
}

\begin{abstract}
Resumo O processo de pintura é fundamental em qualquer indústria automotiva, porém, é complexo e envolve etapas que exigem um controle químico e técnico, o que pode gerar desperdício e influenciar no lead time de entrega do produto final para a etapa seguinte. Este artigo tem como enfoque apresentar uma proposta de redução do lead time em uma linha de pintura automotiva, de forma a adequar o sistema produtivo ao takt time por meio da redução de desperdícios durante o processo de produção. Como base para o estudo, foi realizada uma revisão de literatura a respeito do Sistema Toyota de Produção e o Mapeamento do Fluxo de Valor (MFV). O método adotado para a pesquisa foi o estudo de caso. O estudo foi efetuado em uma empresa multinacional, que atua no setor automotivo premium, na qual se aplicaram as seguintes ferramentas: mapeamento do fluxo de valor (MFV), diagrama de espaguete, estudo de tempos e métodos e gráfico de balanceamento de operadores. Como resultado, obteve-se uma redução de $26 \%$ no lead time total da linha de pintura, bem como, uma redução de $31 \%$ nos estoques entre processos (WIP) e um aumento de 5\% na disponibilidade média da linha. Palavras-chave: Lead time. Pintura Automotiva. Sistema Toyota de Produção.
\end{abstract}

ABstract The painting process is an essential part in any automotive industry. It is complex and involves steps that require chemical and technical control, which can generate waste and influence the lead-time of delivery. This paper focuses on presenting a proposal to reduce lead time in an automotive paint line, in order to adapt the production system to the takt time by means of reducing waste in the production process. As the foundation for the study, a literature review was carried out regarding the Toyota Production System and the Value Stream 
Mapping (VSM). A case study method was conducted in a multinational company that operates in the premium automotive sector, in which the concepts of the Toyota Production System and its tools were applied to identify and optimize the bottleneck station of an automotive paint line, reducing the waste of time and movement of this station and adjusting the painting process to the demands of the next stage. As a result, there was a $26 \%$ reduction in the paint line lead time as well as a 31\% reduction in inter-process inventories and a 5\% increase in average line availability.

Keywords: Lead time. Automotive paint line. Toyota Production System.

Resumen El proceso de pintura es fundamental en cualquier industria automotriz, es complejo e involucra etapas que requieren un control químico y técnico, lo que puede generar desperdicio e influir en el lead time de entrega del producto final para el paso siguiente. Este artículo tiene como enfoque presentar una propuesta de reducción del lead time en una línea de pintura automotriz, de forma a adecuar el sistema productivo al takt time por medio de la reducción de desperdicios durante el proceso de producción. Como base para el estudio, se realizó una revisión de literatura acerca del Sistema Toyota de Producción y el Mapeo del Flujo de Valor (MFV). El método adoptado para la investigación fue el estudio de caso. El estudio fue efectuado en una empresa multinacional, que actúa en el sector automotriz premium, en la que se aplicaron las siguientes herramientas: mapeo del flujo de valor (MFV), diagrama de espaghetti, estudio de tiempos y métodos y gráfico de balance de operadores. Como resultado, se obtuvo una reducción del $26 \%$ en el lead time total de la línea de pintura, así como una reducción del 31\% en las existencias entre procesos (WIP) y un aumento del 5\% en la disponibilidad media de la línea.

Palabras clave: Lead time. Pintura Automotriz. Sistema Toyota de Producción.

\section{INTRODUÇÃO}

O setor automotivo se caracteriza por ser um segmento representativo para se medir a competitividade de um país, pelo volume de recursos que o setor exige por seu papel de catalizador para outras indústrias correlatas, por sua abrangência a nível mundial e porque corresponde a 12\% do PIB industrial do planeta (RIBEIRO, 2010). Nesse contexto, está cada vez mais frequente a busca pela competitividade entre empresas desse ramo, as quais procuram se destacar em relação a suas concorrentes no mercado, seja baixando os seus preços, oferecendo mais garantias, ou disponibilizando produtos com maior qualidade e rapidez, entre outros aspectos (PIEROZAN, 2001).

Um dos indicadores críticos no mercado automotivo é o lead time de pedido, que é influenciado diretamente pelo lead time de produção. Para esse mercado, de acordo com Nunes (2015), a redução do lead time de produção está relacionada à busca pelo aumento da performance e competitividade da organização. Assim, uma vez que se reduzem os tempos de produção, é possível produzir uma quantidade maior de produtos, bem como diferentes modelos na mesma linha de produção. Entretanto, essa redução de tempo de processo se torna um desafio 
para as indústrias automotivas, pois seu processo produtivo é complexo e passa por várias etapas de controle de qualidade, a fim de garantir que o cliente receba um produto confiável (MESQUITA et al., 2014).

Uma das etapas de grande importância e exigência no momento da fabricação de um automóvel é o processo de pintura. Este é responsável por proteger a superfície da carroceria contra o processo de oxidação e aumentar o apelo visual adicionando cor e brilho, sendo esses pontos de destaque no momento da venda do veículo (STREITBERGER e DÖSSEL, 2008). De forma a ganhar competitividade, as empresas do ramo automotivo vêm desenvolvendo sistemas de pintura automotiva cada vez mais otimizados. Os grandes motivadores para a busca de melhorias nesse setor são: as demandas por novos níveis de qualidade e o aumento das regulamentações legais por produtos e processos mais seguros e sustentáveis. Todavia, essa etapa do processo requer grande controle químico e técnico, além de enfrentar diversos fatores que podem influenciar diretamente no lead time de produção (por ter que seguir e respeitar as questões ambientais e de qualidade e segurança), gerar desperdícios em todo o processo e defeitos sobre a carroceria dos veículos, prejudicando assim a qualidade percebida pelo cliente e impactando diretamente no resultado da montadora (TREVIZAN, 2013).

Nesse sentido, um dos modelos de sistema de produção que tem por objetivo reduzir desperdícios e manter e/ou melhorar a qualidade dos produtos é o Sistema Toyota de Produção (STP). O STP sugere a aplicação de ferramentas que auxiliam na identificação e redução ou eliminação de desperdícios encontrados no sistema produtivo, sendo algumas delas: Mapeamento de Fluxo de Valor (MFV), gráficos de movimentação, fluxogramas e balanceamento de operações (DENNIS, 2008).

Diante desse contexto, o objetivo deste estudo é apresentar uma proposta de redução do lead time em uma linha de pintura automotiva, de forma a adequar o sistema produtivo ao takt time e reduzir os desperdícios durante o processo de produção. $\mathrm{O}$ trabalho utilizou a metodologia de estudo de caso, o qual foi desenvolvido de acordo com as seguintes etapas: análise da situação atual do setor de pintura automotivo da empresa em estudo e identificação dos pontos críticos de desperdício; implantação de melhorias no fluxo produtivo da estação mais crítica da linha de pintura automotiva e proposta de melhorias no fluxo produtivo das demais estações da linha de pintura.

Este artigo está dividido em cinco seções. A primeira, a introdução, a segunda expõe uma abordagem teórica sobre o tema em questão - Sistema Toyota de Produção e o Mapeamento do Fluxo de Valor (MFV). A terceira e quarta apresentam os procedimentos metodológicos de pesquisa utilizados e os principais resultados e discussão, consecutivamente. A quinta, e última, propõe as considerações finais.

\section{FUnDAMENTAÇÃO TEÓRICA}

\subsection{SISTEMA TOYOTA DE PRODUÇÃO}

O Sistema Toyota de Produção (STP), ou Lean Manufacturing (Manufatura Enxuta), surgiu no Japão, no período pós Segunda Guerra Mundial, e busca uma melhor sequência de trabalho 
a fim de agregar valor aos produtos solicitados pelo cliente, oferecendo exatamente o que ele deseja e eliminando desperdícios. Isso se caracteriza, portanto, como um sistema produtivo enxuto (DENNIS, 2008). A literatura do Sistema Toyota de Produção declara que existem mais de 100 ferramentas de Manufatura Enxuta disponíveis, entretanto, indica não haver qualquer maneira sistemática de associar um problema de uma organização a uma ferramenta específica para eliminar esse problema (LIKER e MEIER, 2007).

Muitos são os casos de empresas que aplicaram os princípios e ferramentas do STP que obtiveram ótimos resultados, como é o caso da aplicação feita por Barreto (2012). Barreto conseguiu aumentar o nível de produção de peças em 30\%, diminuiem 52\% o número de horas extras, bem como, reduzir o nível de defeitos de uma indústria de peças automotivas em $42 \%$. Tudo isso por meio da aplicação de estudos e rearranjo de layouts, estudos de tempos e métodos, e métodos para solução de problemas, sendo essas ferramentas do STP.

\subsection{Mapeamento do fluxo de valor}

Para a produção enxuta, o objetivo principal é fazer fluir os materiais por meio dos processos, agregando valor, sem haver interrupções e desperdícios, até que cheguem ao cliente satisfazendo todas as necessidades do mesmo. Isso significa levar em conta os processos num sentido amplo (e não apenas em processos individuais), buscando melhoria global da cadeia de processamento. A criação de um fluxo de valor enxuto é uma parte fundamental para se conseguir atingir o objetivo principal da produção enxuta (QUEIROZ et al., 2004).

Nesse contexto, para criar um fluxo de valor enxuto, pode-se aplicar a técnica do Mapeamento de Fluxo de Valor (MFV), que compreende o mapeamento do fluxo de materiais e informações ao longo do processo produtivo. Segundo Liker e Meier (2007), a realização do MFV depende da observação de um processo com as atividades, materiais e fluxo de informação em formato de linha do tempo, e mapeá-las do início ao fim. Por meio desse procedimento, encontra-se uma elevada quantidade de perdas, geralmente maior que as atividades que agregam valor ao cliente. As etapas para aplicação do MFV são representadas na Figura 1.

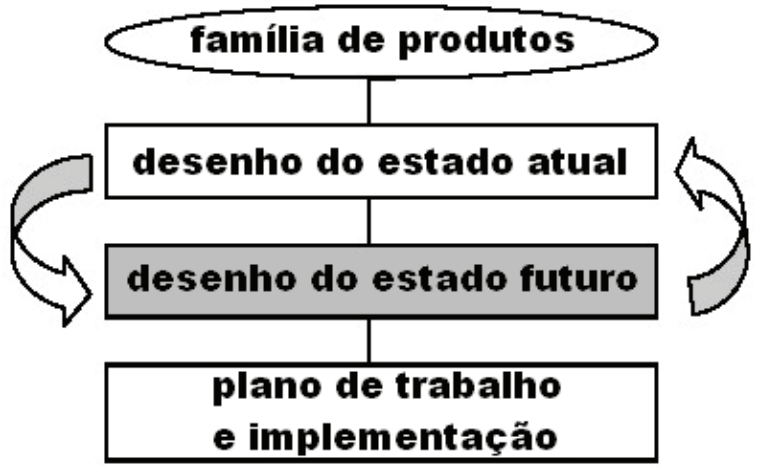

Figura 1: Etapas de aplicação do MFV.

Fonte: Liker e Meier (2007). 
A metodologia do MFV pode ser aplicada em linhas de montagem na redução de custos, mão de obra, entre outros benefícios, como fizeram Mesquita et al. (2014). Esses autores desenvolveram o MFV em uma área de abastecimento de linhas de montagem de uma indústria automotiva, conseguindo reduzir o custo de mão de obra do setor em $\mathrm{R} \$ 28.248,00$ por ano. Além disso, melhorou-se a qualidade de vida dos trabalhadores do departamento por meio de mudanças ergonômicas e obteve-se um maior controle das peças abastecidas nas estações a partir da implantação de um sistema Kanban.

O primeiro passo para realizar o mapeamento da situação atual é definir a família de produtos que serão mapeados e analisados. De acordo com Queiroz et al. (2004), após ser selecionada a família de produtos, coletam-se os dados de processo que auxiliem na visualização e análise da situação atual da família de produtos. Com essas informações, desenha-se o mapa de estado atual da família de produtos selecionados, com a utilização de alguns ícones (Figura 2), sugeridos por Rother e Shook (2003).
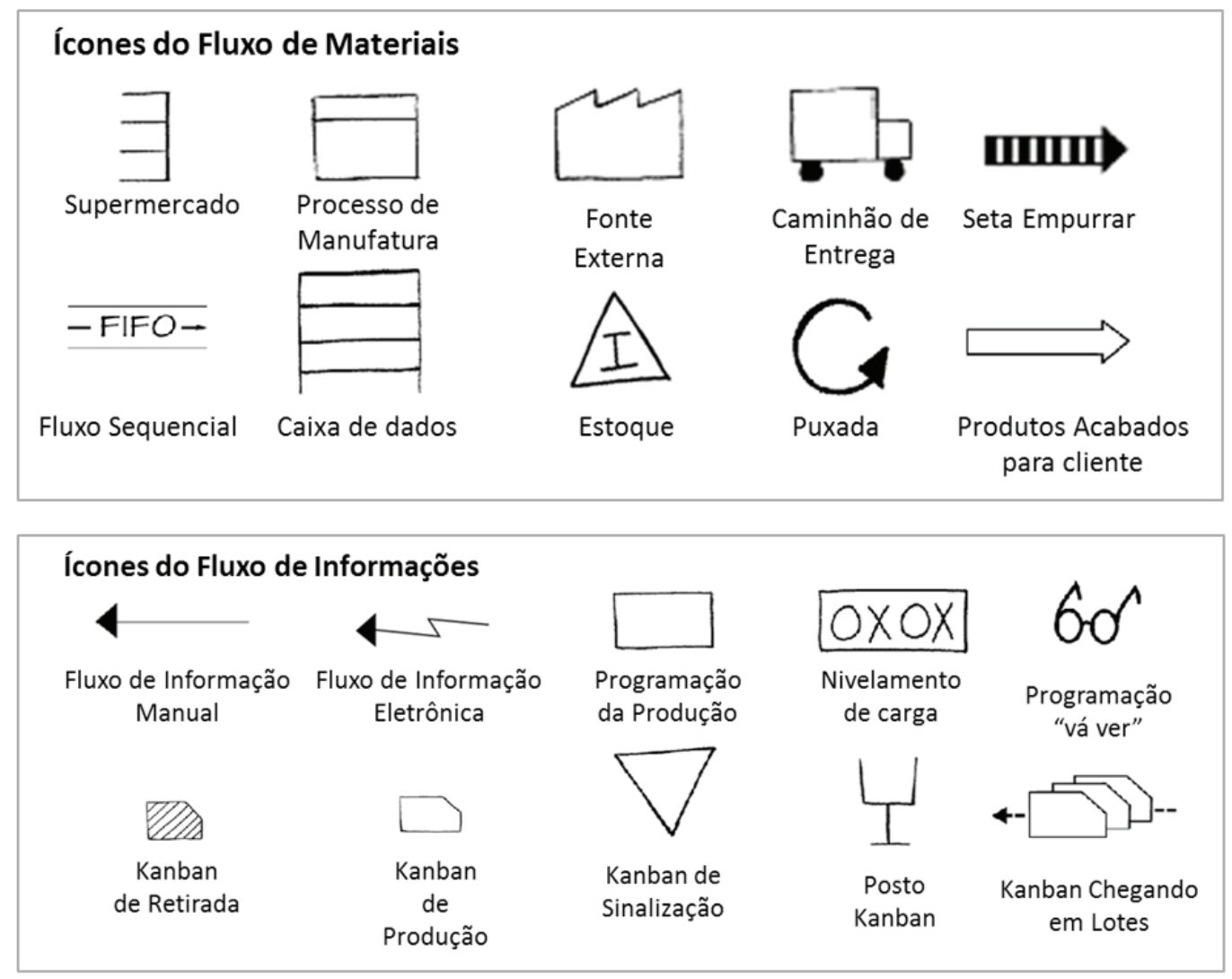

Figura 2: Ícones utilizados na representação do MFV.

Fonte: Rother e Shook (2003). 
Após obter a situação atual, inicia-se o planejamento e desenho do mapa do estado futuro. Segundo Kach et al. (2014), o desenho do estado futuro deverá se basear na aplicação de ferramentas de qualidade e de controles de produção, focando o menor custo para a adequação do sistema, de forma a extinguir as falhas e desperdícios identificados no decorrer do processo produtivo. Ao final, com o mapa futuro em mãos, é preciso implantá-lo rapidamente com o apoio de um plano, o qual deve conter metas mensuráveis, responsáveis, nomeadas e com datas definidas (ROTHER e SHOOK, 2003).

Essa ferramenta tem sido amplamente aplicada em diversas áreas, desde serviços (CHANESKI, 2012; MUCHFIRODIN, 2013), escritórios (CALSAVARA, 2016; CHAVEZ et al., 2018) e principalmente na manufatura (FAULKNER; BADURDEEN, 2014; SATISH et al., 2015). Destacam-se os resultados de Krushnaraj et al. (2016) que, a partir da aplicação do MVF em uma indústria automotiva, conseguiu diminuir o lead time em 42\% (de 7,6 para 3,2 dias) e o tempo de ciclo em 73\%. Tais resultados são expressivos em um setor em que produzir com qualidade em pouco tempo é fundamental.

\section{Procedimentos metodológicos}

Segundo Miguel et al. (2011), a abordagem qualitativa busca obter informações na perspectiva dos indivíduos, bem como, interpretar o ambiente em que a problemática acontece, podendo o pesquisador visitar a organização pesquisada, fazer observações e coletar evidências. Nesse contexto, o trabalho em questão se classifica como qualitativo, uma vez que procura identificar os pontos críticos dentro de uma linha de pintura automotiva e analisar os tempos, métodos e movimentações das atividades ou estações de trabalho que foram classificados como mais críticas.

Para tanto, utilizou-se o método de estudo de caso, o qual, segundo Miguel et al. (2011), investiga determinado fenômeno, geralmente contemporâneo, dentro de um contexto real de vida, quando as fronteiras entre o fenômeno e o contexto em que ele se insere não são claramente definidas. Assim, esse método de pesquisa mostrou-se adequado ao presente estudo, uma vez que os pesquisadores procuraram melhor entender o problema, visando estimular a compreensão, sugerindo hipóteses e ações de melhoria nas mesmas e identificando ainda uma situação futura para a linha de pintura automotiva em questão.

\subsection{Etapas do estudo}

De acordo com Miguel (2007), o processo de estudo de caso acontece em seis fases (Figura 3): definir uma estrutura conceitual teórica, planejar o caso, conduzir teste piloto, coletar dados, analisar os dados e gerar relatórios. 


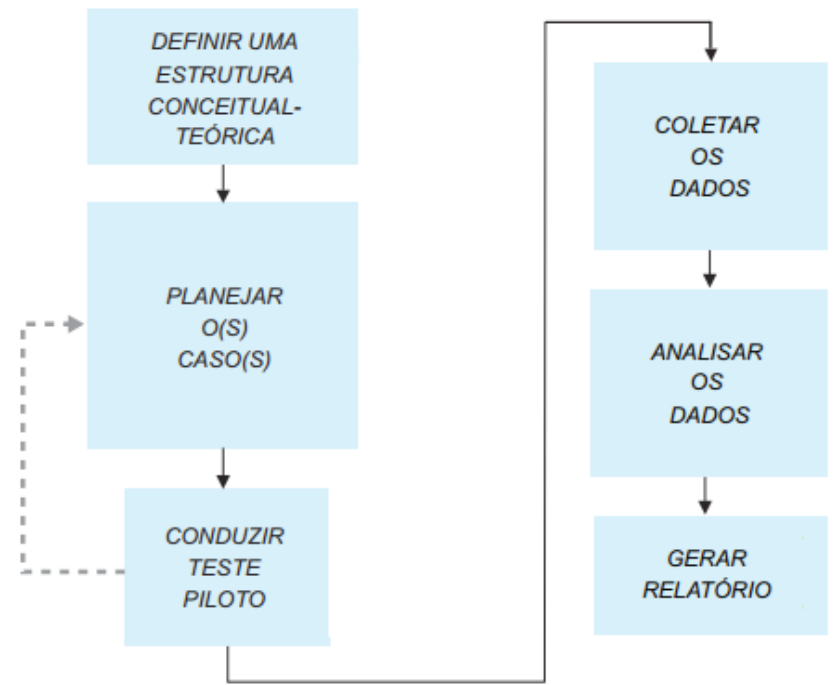

Figura 3: Etapas para desenvolvimento do estudo de caso.

Fonte: Miguel (2007).

O estudo foi realizado no decorrer do primeiro semestre de 2016 e envolveu uma equipe de trabalho composta pela gerência de fábrica, supervisores de linha e analistas do processo. Para a elaboração, na fase de definição da estrutura conceitual teórica, foi feita uma revisão de literatura dos assuntos pertinentes ao tema: Sistema Toyota de Produção (Lean Production) e Mapeamento do Fluxo de Valor (MFV). Na fase de planejamento do caso e condução do teste piloto, foi selecionado um modelo de carroceria de maior retorno financeiro para a organização. Para a fase de coleta de dados, foi identificado o fluxo atual de produção desse modelo no setor de pintura e caracterizados os pontos de desperdício, onde foi possível identificar a estação mais crítica da linha de pintura.

A fase de análise de dados foi realizada por meio da identificação da estação mais crítica, onde foram aplicados estudos de tempos e métodos e desenvolvidas fichas de cronoanálise (Apêndices A e B), bem como, um estudo de layout e a elaboração de gráficos espaguete na mesma (com a utilização do software DraftSight) - Figura 7. Tais ações permitiram identificar tarefas que reduzissem o tempo para execução do trabalho, racionalizando os movimentos e operações, bem como, ter um melhor aproveitamento do layout da estação e balancear as atividades entre os operadores. Após ter levantado e planejado as tarefas, as mesmas foram implantadas na estação mais crítica, onde foram feitas novas fichas de cronoanálise e um novo gráfico espaguete, com o objetivo de avaliar os resultados e comprovar a eficácia das ações implantadas.

Já para as demais estações da linha de pintura, foram levantadas ações de melhoria, propondo ao final, nas fases de avaliação de resultados e geração de relatórios, uma análise dos dados obtidos e uma situação futura que aperfeiçoasse o processo de produção. Todos os dados citados neste estudo foram multiplicados por um fator aleatório " $\mathrm{x}$ ", de forma que não exponha a empresa estudada. 


\section{Resultados e discussão}

Indústrias automotivas da atualidade possuem sistemas de pintura robotizados que garantem uma maior qualidade e segurança ao produto final, uma vez que há poucas interferências manuais. Em razão dos últimos desenvolvimentos em tecnologias e máquinas de pintura, processos de limpeza automatizados e tintas modernas, o tempo gasto para finalizar o processo de pintura pode ser menor que oito horas (SVEJDA, 2012). Para tanto, de forma a evitar que carros com erros de qualidade sejam distribuídos para o mercado, as indústrias automotivas utilizam estações de inspeção de qualidade no final de cada processo crítico; quando erros são detectados, elas procuram corrigi-los internamente, gerando retrabalhos (MACHADO, 2013). Tais retrabalhos são comuns e consomem tempo de produção, conforme demonstra uma pesquisa survey feita com sete indústrias automotivas por Howard (2000). Esse autor expõe que, em média, $28 \%$ de todos os veículos fabricados no processo de pintura são retrabalhados de alguma forma, e que $4 \%$ de todos os veículos necessitam ser retirados da linha e retornados a estações anteriores para serem retrabalhados. Isso consome, em média, 38 minutos por veículo.

Assim como a qualidade, o impacto ambiental gerado pelos processos de pintura automotiva também é outro fator que vem sendo estudado e cobrado da indústria automotiva. De acordo com Howard (2000), a pintura é o setor que mais pode causar problemas ambientais em todo o processo de fabricação de um carro. De forma a prevenir esses problemas, as indústrias automotivas gastam grandes quantias com tratamentos de ar, água e esgoto, bem como, com operações mais limpas, uma vez que os custos com energia e materiais são altos para realizarem esses tratamentos. Dentro desse cenário, pelo fato de o processo de pintura automotiva ter de seguir e respeitar as questões ambientais e de qualidade e segurança, o lead time de produção nesse setor é diretamente comprometido.

A área de pintura da empresa estudada produz atualmente alguns modelos de carrocerias, e a cada ano são inseridos novos modelos. Entretanto, a principal demanda do setor gira em torno de três modelos de carrocerias, que serão identificados como carrocerias Modelo X, Y e Z. De acordo com Queiroz et al. (2004), a primeira etapa para a elaboração de um mapeamento de fluxo de valor é selecionar uma família de produtos. Nesse contexto, o critério de escolha da família de carrocerias se baseou em uma análise de demanda por valor de mercado das carrocerias, uma vez que todos os três modelos passam por todos os processos executados no setor de pintura. Dessa forma, foram pesquisados os valores de mercado médio para cada modelo, bem como, as demandas em unidades previstas para o ano. A Tabela 1 detalha as informações de valor unitário médio e consumo anual revisto para cada um dos modelos citados. A partir dos dados obtidos, pode-se constatar que a carroceria Modelo Y representa 51\% do valor de mercado para a empresa estudada, a qual foi escolhida para o estudo. 
Tabela 1: Informações sobre os modelos produzidos.

\begin{tabular}{ccccc}
\hline Modelo & $\begin{array}{c}\text { Consumo } \\
\text { Previsto (Un.) }\end{array}$ & Valor un. & Valor Total & \% Total \\
\hline $\mathrm{Y}$ & 1198 & $\mathrm{R} \$ 181.285,50$ & $\mathrm{R} \$ 217.180 .029,00$ & $51 \%$ \\
\hline $\mathrm{Z}$ & 796 & $\mathrm{R} \$ 183.450,00$ & $\mathrm{R} \$ 146.026 .200,00$ & $34 \%$ \\
\hline $\mathrm{X}$ & 360 & $\mathrm{R} \$ 182.500,00$ & $\mathrm{R} \$ 65.700 .000,00$ & $15 \%$ \\
\hline
\end{tabular}

Fonte: Próprio autor, 2017.

\subsection{Cenário atual da linha de pintura completa}

O segundo passo para o desenho da situação atual foi coletar informações de chão de fábrica e produtividade. As etapas de produção de um veículo podem ser resumidas em quatro grandes setores, seguindo a ordem de produção: estamparia, carroceria, pintura e montagem. Tendo como foco o setor de pintura, observa-se que o fornecedor do processo é o setor de carroceria e o cliente é o setor de montagem. Em seguida, por meio de uma reunião com o departamento de planejamento da pintura, foram coletados os dados de quantidade de carros por dia que deveriam ser produzidos (75 carrocerias), quais as frequências de entrega para o setor da pintura (entregas diárias) e a quantidade de horas disponíveis no dia (1 turno de 9 horas, revezando no horário de almoço e descontando 15 min. de descanso). Com esses dados, foi possível calcular o tempo takt de todo o processo, o qual resultou em $7 \mathrm{~min}$./carroceria.

$\mathrm{Na}$ sequência, foram realizadas visitas ao setor de pintura para identificar o fluxo de produção atual, onde o processo de produção de uma carroceria nesse setor envolve a execução de várias operações em 19 estações de trabalho (Figura 4), e todos os modelos que são produzidos no setor em questão passam por todas elas, diferenciando somente as operações executadas em cada estação.

Após isso, mediu-se o tempo de ciclo para cada uma das estações de trabalho, nas quais, à medida que as medições de tempo eram feitas, pôde-se observar os estoques gerados entre os processos produtivos. Foram selecionados os valores de estoque encontrados em dias em que a linha estava trabalhando em seu potencial máximo e sem grandes paradas de produção. Nesse momento, foi possível também levantar o número de operadores que trabalhavam nas estações.

Para a análise de cada estação de trabalho, foi preciso também verificar a disponibilidade de cada estação. Essa informação foi obtida pelo cálculo percentual do número de minutos trabalhados no mês sobre o número de minutos disponíveis, utilizando dados históricos de paradas de linha do setor no mês de análise. Essas paradas foram classificadas em quatro tipos: paradas de manutenção - quando era realizada alguma manutenção preventiva, corretiva ou preditiva na estação de trabalho; paradas de planejamento - quando era feito algum treinamento na estação ou carro de teste que passava pela mesma; paradas de produção - quando a estação anterior ou posterior estava com problemas e interferia na produtividade da estação atual e, paradas de qualidade - quando algum erro de qualidade era encontrado no produto e precisava ser corrigido. As disponibilidades mensais obtidas para cada estação podem ser verificadas na Tabela 2. 


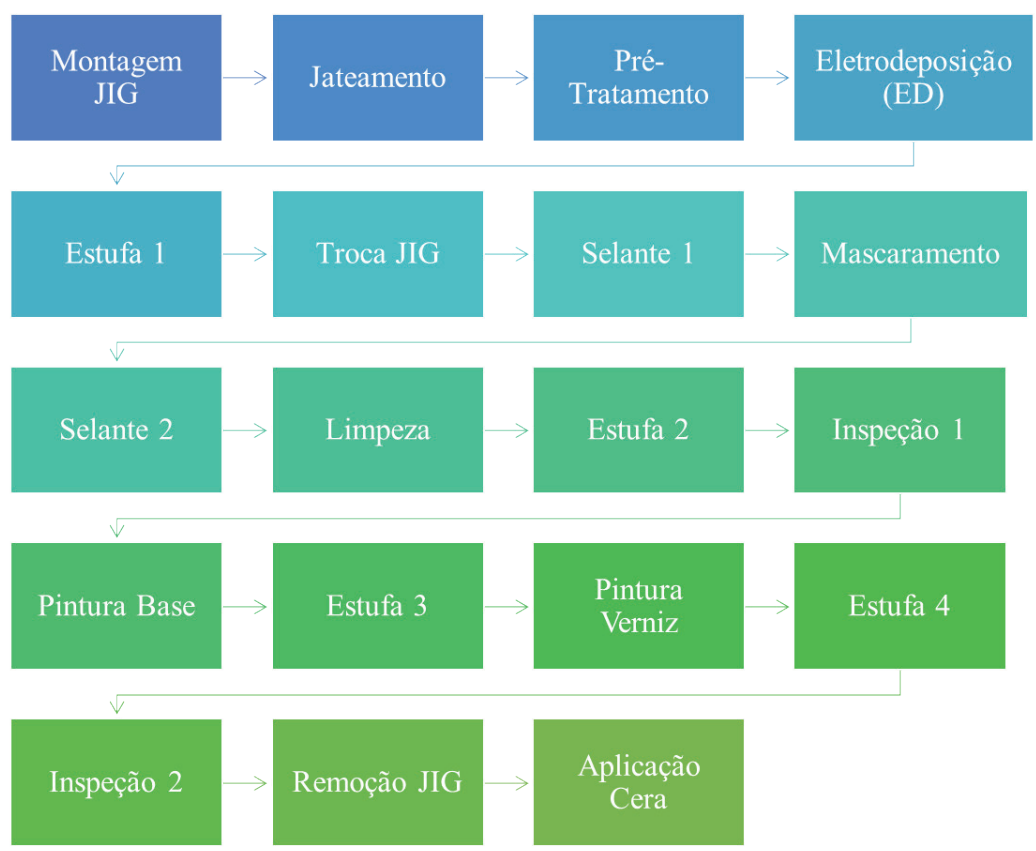

Figura 4: Estações de trabalho da linha de pintura automotiva.

Fonte: Próprio autor, 2017.

Tabela 2: Disponibilidade das estações de trabalho.

\begin{tabular}{|c|c|c|c|c|c|c|c|}
\hline \multirow[b]{2}{*}{ Estações } & \multicolumn{5}{|c|}{ Tempo de parada/ Motivo (min.) } & \multirow{2}{*}{$\begin{array}{c}\text { Tempo } \\
\text { Disponível } \\
\text { (min.) }\end{array}$} & \multirow[b]{2}{*}{ Disponibilidade } \\
\hline & Manut. & Planej. & Prod. & Qual. & $\begin{array}{r}\text { Total } \\
\text { (min.) }\end{array}$ & & \\
\hline Montagem JIG & 750 & 153 & 232 & & 1135 & 11550 & $90 \%$ \\
\hline Jateamento & 578 & & & & 578 & 11550 & $95 \%$ \\
\hline Pré-tratamento & 1208 & & & & 1208 & 11550 & $90 \%$ \\
\hline Eletrodep. (ED) & 890 & 257 & & & 1147 & 11550 & $90 \%$ \\
\hline Estufa 1 & 523 & & & & 523 & 11550 & $95 \%$ \\
\hline Troca JIG & 345 & 730 & 130 & & 1205 & 11550 & $90 \%$ \\
\hline Selante 1 & 645 & 120 & & 357 & 1122 & 11550 & $90 \%$ \\
\hline Mascaramento & 612 & & 600 & & 1212 & 11550 & $90 \%$ \\
\hline Selante 2 & 472 & & 36 & 65 & 573 & 11550 & $95 \%$ \\
\hline Limpeza & 315 & & & 430 & 745 & 11550 & $94 \%$ \\
\hline Estufa 2 & & 150 & & & 150 & 11550 & $99 \%$ \\
\hline Inspeção 1 & 167 & & & 1012 & 1179 & 11550 & $90 \%$ \\
\hline Pintura Base & 585 & & & & 585 & 11550 & $95 \%$ \\
\hline Estufa 3 & & & & & 0 & 11550 & $100 \%$ \\
\hline Pintura Verniz & 315 & 236 & & & 551 & 11550 & $95 \%$ \\
\hline Estufa 4 & & & & & 0 & 11550 & $100 \%$ \\
\hline Inspeção 2 & 197 & & 340 & 1145 & 1682 & 11550 & $85 \%$ \\
\hline Remoção JIG & 22 & & & & 22 & 11550 & $100 \%$ \\
\hline Aplicação Cera & 235 & 876 & & & 1111 & 11550 & $90 \%$ \\
\hline
\end{tabular}

Fonte: Próprio autor, 2017. 
Para o desenho do mapa da situação atual do modelo selecionado, não foi considerado o tempo de troca ou setup de cada estação, uma vez que, para diferentes modelos de carroceria que são produzidos em cada estação, a operação executada nesta é a mesma. No momento da troca de modelo, a mudança ocorre somente nos locais de aplicação e inspeção, o que chega a influenciar no tempo de ciclo, mas não existindo tempo de troca ou setup. De acordo com Rother e Shook (2003), o intuito de utilizar a ferramenta de mapeamento de fluxo de valor em processos ou serviços é possibilitar a visualização dos desperdícios do processo produtivo (Tabela 2), foi possível desenhar o mapa da situação atual do modelo Y, representado e estações gargalos para que se possa estabelecer um estado futuro de modo a otimizar o processo.

Conforme a Figura 5, todo o processo de produção da carroceria modelo Y no setor de pintura tem um tempo de processamento de 133 minutos (2 horas e 13 min.). Entretanto, se forem somados a esse valor 476 minutos (7 horas e 56 min.), que é o tempo das carrocerias que ficam em estoques entre processos, resultará um lead time de 609 minutos $(10$ horas e 9 min.). Segundo Svejda (2012), para um processo de pintura automotiva, o lead time obtido acaba sendo 2 horas e 9 minutos a mais que o tempo normal de produção, considerando que um carro deve sair do setor de carrocerias, ser produzido e entregue para o setor de montagem, em média, em 8 horas.

\subsection{Otimização da estação mais crítica do sistema}

Com o desenho mapa do estado atual em mãos, percebeu-se que era necessário reduzir os tempos de ciclo das estações críticas do processo, bem como, os estoques entre os processos gerados pelas mesmas. De acordo com Gori (2012), o gráfico de balanceamento de operações é uma ferramenta que possibilita a melhor distribuição de operações entre os operadores ou postos de trabalho, caso um dos mesmos esteja sobrecarregado. Todavia, o balanceamento de linha entre as estações não se mostrou uma opção viável, pois a distribuição das operações realizadas nas estações críticas para as outras estações só seria possível com grandes investimentos para adaptar essas estações às novas operações. 


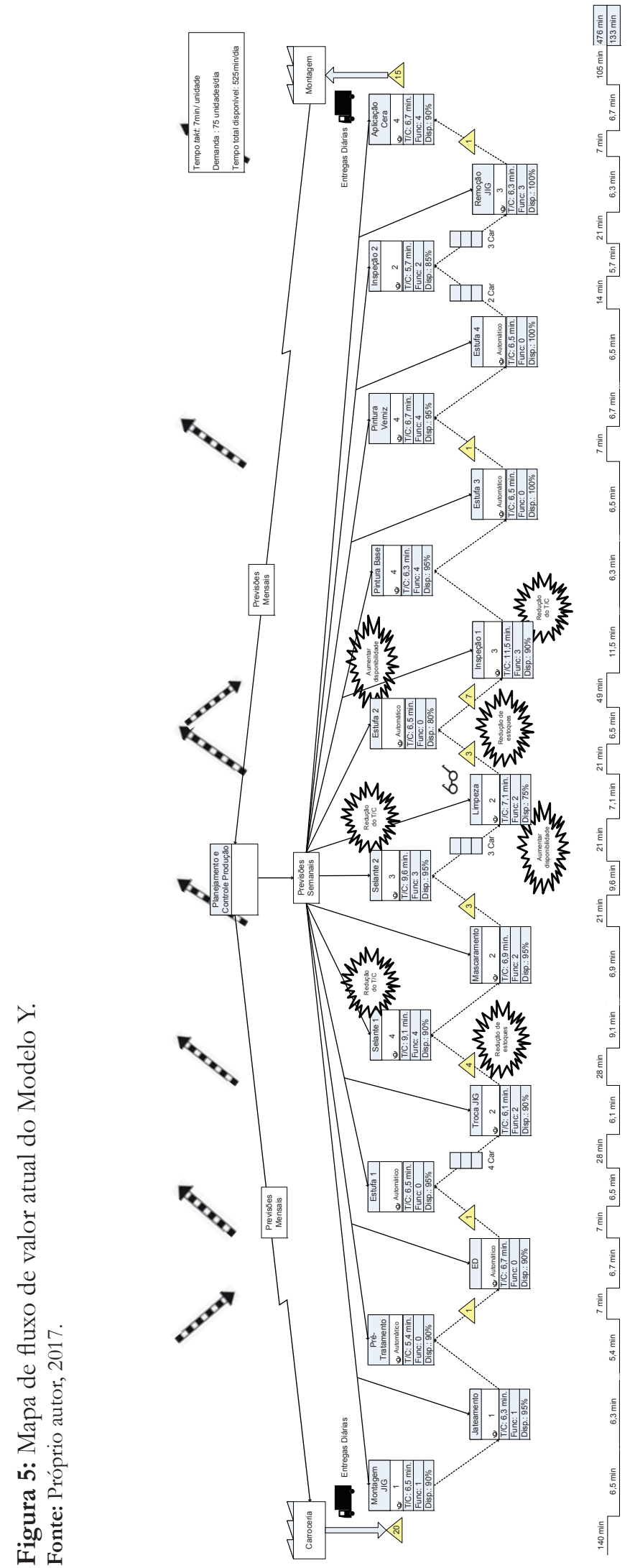


Além disso, estas não conseguiriam absorver e efetuar as atividades realizadas nas estações críticas, uma vez que seus tempos de ciclo são muito próximos do tempo takt. Sendo assim, definiu-se a estação Inspeção 1 como crítica, pois seu tempo de ciclo foi o de maior diferença (4,5 min.) em relação ao tempo takt (7 min./unid.).

A partir de observações e filmagens, verificou-se que todo o processo executado na estação de Inspeção 1 era dividido em três operadores, dos quais um ficava responsável pelo lado direto da carroceria, outro pelo lado esquerdo, e o terceiro era um operador absenteísta. O último era responsável por correções de eventuais defeitos de qualidade que teriam chegado à estação, como amassados na carroceria ou bolhas nos cordões de selante passados nas portas, porta-malas e capô.

\subsubsection{Estudo de tempos, métodos e de layout da estação mais crítica}

De forma a obter informações mais detalhadas do processo executado na estação e dos pontos de desperdício citados, foram aplicadas técnicas de estudos de tempos e métodos no setor. Por meio das observações e filmagens feitas da estação, foram separadas as ações executadas de cada um dos operadores e classificadas essas ações em operação, transporte ou movimentação, inspeção, espera ou armazenagem, de acordo com a simbologia padrão da ASME (BATISTA et al., 2006).-

Com as informações obtidas das fichas de cronoanálise de cada posto da estação de Inspeção 1 e com medições do layout da estação de trabalho, foi elaborado um gráfico espaguete do setor, demonstrando os caminhos percorridos de cada um dos operadores na execução das operações (Figura 6a). As distâncias percorridas por todos os operadores estão detalhadas na Tabela 3.

a)

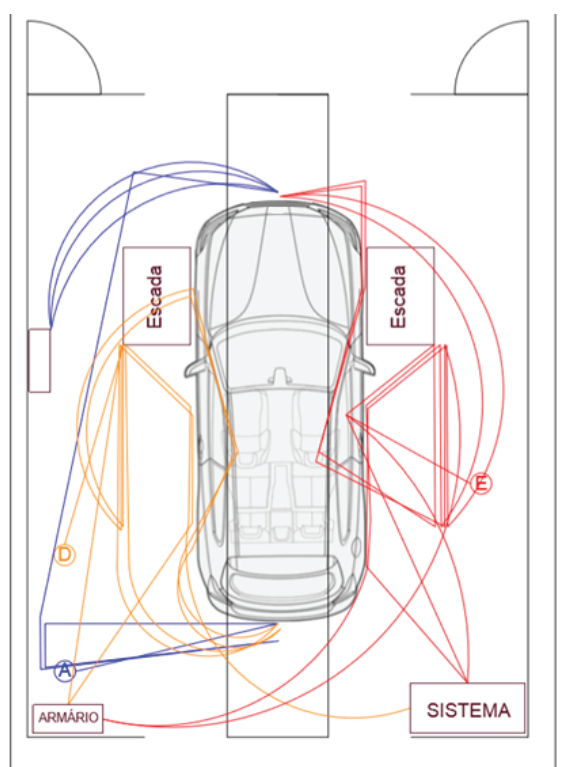

b)

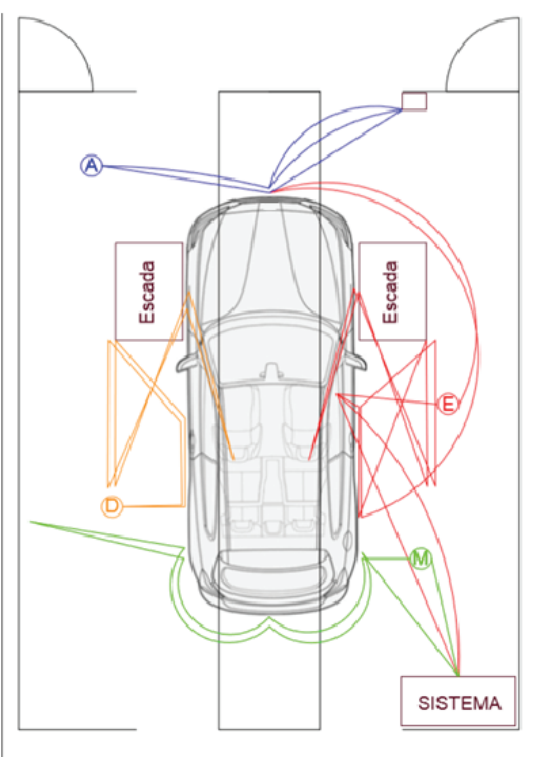

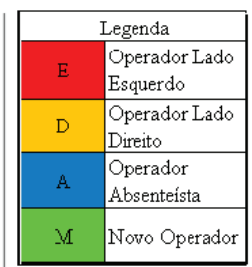

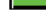

Figura 6: Gráfico espaguete da movimentação dos operadores da estação de Inspeção 1 a) situação atual, b) após melhorias e balanceamento de operações.

Fonte: Próprio autor, 2017. 
Tabela 3: Distâncias percorridas para a realização das operações na estação Inspeção 1.

\begin{tabular}{ccc}
\hline Operador & Etapa & Distância Percorrida (metros) \\
\hline \multirow{2}{*}{ Lado Direito } & Inspeção e Lixamento & 33,6 \\
\cline { 2 - 3 } & Limpeza & 22,4 \\
\hline \multirow{2}{*}{ Lado Esquerdo } & Inspeção e Lixamento & 28,8 \\
\cline { 2 - 3 } & Limpeza & 19,2 \\
\hline Absenteísta & Correção de defeitos & 34 \\
\hline
\end{tabular}

Fonte: Próprio autor, 2017.

Analisando as fichas de cronoanálise obtidas, observou-se que os operadores que trabalham no lado esquerdo e direito da carroceria realizam muitas movimentações para a execução das operações, as quais somadas representam em média 20\% do tempo de ciclo de todo o processo (cálculo feito por meio da divisão da soma das ações dos operadores que foram classificadas como movimentação do diagrama de fluxo pelo tempo total de operação). Essas movimentações poderiam ser reduzidas ou eliminadas com a alteração do posicionamento dos materiais na estação e com a modificação da sequência do processo realizado. Todas as ações tomadas para a redução de desperdício na estação Inspeção 1 foram resumidas no Quadro 1.

Com as reduções de desperdícios aplicadas, foi preenchida uma nova ficha de cronometragem das operações de cada operador e se verificou que houve uma redução de $5 \%$ no tempo de operação do operador do lado esquerdo, 10\% no tempo de operação do lado direito e de $3 \%$ do operador absenteísta. Entretanto, os tempos de operação dos operadores das laterais esquerda e direita ainda excediam o tempo takt em 3,86 min. e 2,1 min., respectivamente.

Como já haviam sido reduzidos ao máximo os desperdícios identificados, os operadores das laterais ainda estavam com o tempo de operação maior que o tempo de ciclo, bem como, não era possível dividir essas atividades com o absenteísta, por conta do pouco tempo restante desse operador. Optou-se, assim, por inserir mais um operador na linha e redistribuir as atividades das laterais com o mesmo. Essa ação pôde ser justificada pela aplicação do cálculo do número de operadores sugerida por Tapping et al. (2002), em que se dividiu a soma dos tempos de operação de todos os operadores da estação pelo tempo tak.t. O resultado obtido foi de 3,78, o qual, segundo Tapping et al. (2002), para valores decimais maiores que 0,5 , o número deve ser arredondado para cima, resultando em quatro operadores.

Dessa forma, foram distribuídas as operações realizadas pelos funcionários das laterais com o novo operador da estação, de forma que a execução da operação do mesmo não influenciasse na operação dos demais. Outro ponto que auxiliou no balanceamento de operações entre os operadores da estação foi que o time de qualidade formado trabalhou na correção de alguns parâmetros de processo do setor e conseguiu reduzir os defeitos de amassado para zero e os defeitos de bolhas no selante ficaram concentrados somente no capô. Isso fez que o operador absenteísta ficasse com um tempo livre maior e pudesse executar operações dos outros operadores da estação. 
Quadro 1: Ações para a redução de desperdício feitas na estação de Inspeção 1.

Ações de redução de desperdício estação Inspeção 1

\begin{tabular}{|c|c|c|c|}
\hline Ação & Antes & Depois & Melhoria \\
\hline $\begin{array}{l}\text { a) Definição de uma } \\
\text { sequência padrão de } \\
\text { processo (operadores } \\
\text { laterais) }\end{array}$ & $\begin{array}{l}\text { - Sem sequência definida; } \\
\text { - } 15 \text { operações e quatro } \\
\text { movimentações com a } \\
\text { escada; }\end{array}$ & $\begin{array}{l}\text { - Sequência padrão de } \\
\text { processo definida para } \\
\text { as laterais; } \\
\text { - } 13 \text { operações com } \\
\text { duas movimentações de } \\
\text { escada; }\end{array}$ & $\begin{array}{l}\text { - Redução da } \\
\text { movimentação da escada } \\
\text { no setor; } \\
\text { - Redução da } \\
\text { movimentação dos } \\
\text { operadores na execução das } \\
\text { operações; }\end{array}$ \\
\hline $\begin{array}{l}\text { b) Centralização } \\
\text { cadastro de defeitos } \\
\text { no sistema }\end{array}$ & $\begin{array}{l}\text { - Os dois operadores } \\
\text { das laterais inseriam os } \\
\text { lixamentos feitos e defeitos } \\
\text { encontrados no sistema; } \\
\text { - Maior movimentação } \\
\text { operador da direita, pois o } \\
\text { sistema se encontra do lado } \\
\text { esquerdo da estação; }\end{array}$ & $\begin{array}{l}\text { - Cadastro de todos } \\
\text { os pontos lixados e } \\
\text { defeitos encontrados } \\
\text { feito pelo operador da } \\
\text { esquerda (mais próximo } \\
\text { do sistema); }\end{array}$ & $\begin{array}{l}\text { - Redução da } \\
\text { movimentação do operador } \\
\text { da direita; } \\
\text { - Centralização do } \\
\text { cadastro dos defeitos e } \\
\text { pontos de lixamento; }\end{array}$ \\
\hline $\begin{array}{l}\text { c) Suporte Álcool } \\
\text { Isopropílico }\end{array}$ & $\begin{array}{l}\text { - Álcool isopropílico } \\
\text { localizado em um armário } \\
\text { na lateral direita da estação; } \\
\text { - Operadores tinham de ir } \\
\text { até o armário para pegar o } \\
\text { álcool isopropílico; }\end{array}$ & $\begin{array}{l}\text { - Suporte para o álcool } \\
\text { isopropílico no braço } \\
\text { das escadas das laterais } \\
\text { esquerda e direita; }\end{array}$ & $\begin{array}{l}\text { - Redução da } \\
\text { movimentação para pegar o } \\
\text { álcool isopropílico; } \\
\text { - Maior praticidade } \\
\text { no início da limpeza da } \\
\text { carroceria; }\end{array}$ \\
\hline $\begin{array}{l}\text { d) Suporte materiais } \\
\text { correção de bolhas de } \\
\text { selante }\end{array}$ & $\begin{array}{l}\text { - Materiais de correção } \\
\text { de bolhas de selante } \\
\text { localizados na lateral direita } \\
\text { da estação; } \\
\text { - Operador tinha de ir até } \\
\text { a lateral direita para retirar } \\
\text { os materiais e voltar para o } \\
\text { local de correção. }\end{array}$ & $\begin{array}{l}\text { - Suporte para os } \\
\text { materiais de correção } \\
\text { de bolhas na saída da } \\
\text { estação (mais perto do } \\
\text { capô onde o número de } \\
\text { bolhas era maior). }\end{array}$ & $\begin{array}{l}\text { - Redução da } \\
\text { movimentação para pegar } \\
\text { os materiais; } \\
\text { - Maior praticidade ao } \\
\text { executar a atividade de } \\
\text { correção de bolhas. }\end{array}$ \\
\hline
\end{tabular}

Fonte: Próprio autor, 2017.

A partir do novo balanceamento das operações, foram feitas novas fichas de cronoanálise e elaborado um novo gráfico espaguete (Figura 6b), onde se verificou uma redução média de $46 \%$ da movimentação dos operadores (Tabela 4), assim como, uma redução dos tempos de operação dos operadores das laterais esquerda e direita em torno de 46\% e 27\%, respectivamente (Figura 7). Com a aplicação das melhorias propostas e com a entrada do novo operador, a estação de Inspeção 1 passou a ter um tempo de ciclo de 6,9 min., podendo produzir de acordo com o tempo takt. 
Tabela 4: Comparação da movimentação antes e depois das melhorias.

\begin{tabular}{clccc}
\hline \multirow{2}{*}{ Operador } & \multicolumn{1}{c}{ Etapa } & Distância antes (m) & Distância depois (m) & Diferença \\
\hline \multirow{2}{*}{ Lado Direito } & Inspeção e Lixamento & 33,6 & 20,4 & $39 \%$ \\
\cline { 2 - 5 } & Limpeza & 22,4 & 13,6 & $39 \%$ \\
\hline \multirow{2}{*}{ Lado Esquerdo } & Inspeção e Lixamento & 28,8 & 10,2 & $65 \%$ \\
\cline { 2 - 5 } & Limpeza & 19,2 & 6,8 & $65 \%$ \\
\hline \multirow{2}{*}{ Absenteísta } & $\begin{array}{l}\text { Inspeção, lixamento, } \\
\text { limpeza e Correção de } \\
\text { defeitos }\end{array}$ & 34 & 9 & $74 \%$ \\
\hline \multirow{2}{*}{$\begin{array}{l}\text { Novo } \\
\text { Associado }\end{array}$} & Inspeção e Lixamento & - & 8,4 & - \\
\cline { 2 - 5 } & Limpeza & - & 5,6 & - \\
\hline \multicolumn{2}{c}{ Total percorrido (m) } & 138 & 74 & $46 \%$ \\
\hline
\end{tabular}

Fonte: Próprio autor, 2017.

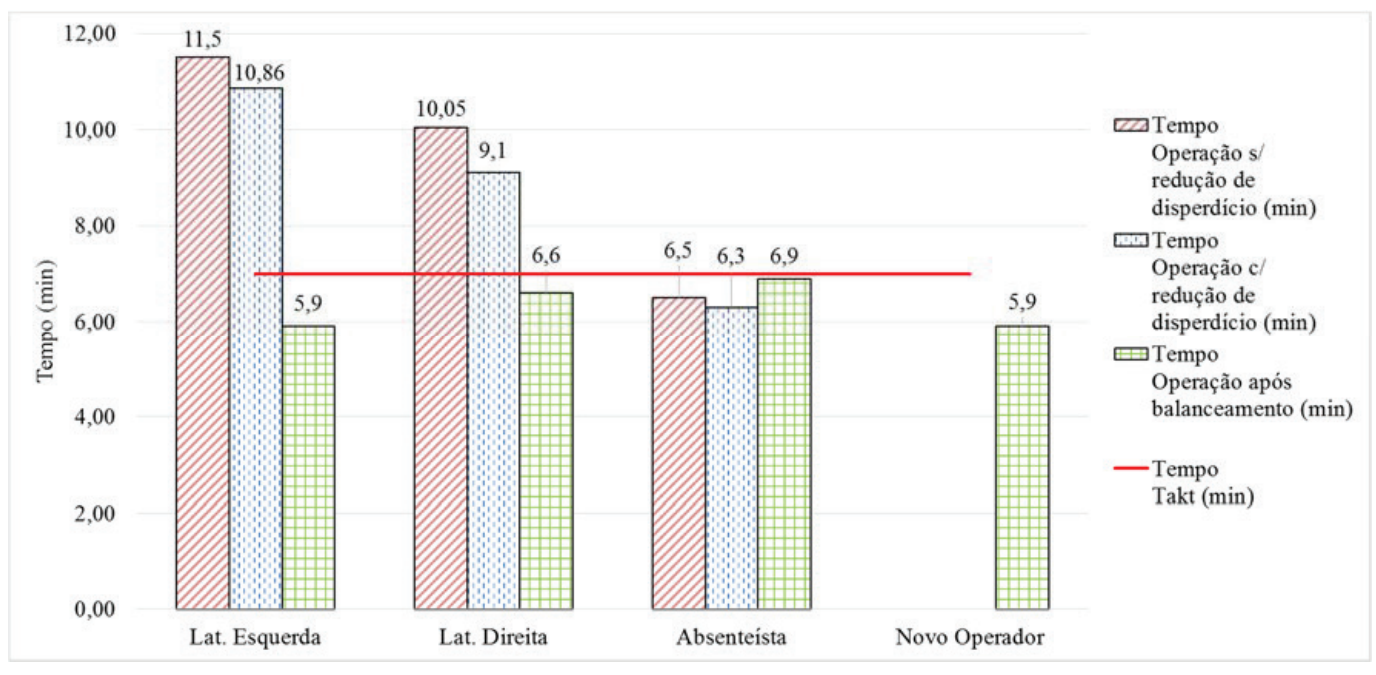

Figura 7: Tempos de operação Inspeção 1, após balanceamento de operações.

Fonte: Próprio autor, 2017.

\subsection{CenáRIO FUtURO dA LINHA DE PINTURA COMPLETA}

Para o desenho do mapa de fluxo de valor futuro, procurou-se seguir as regras coerentes com os princípios enxutos citados por Queiroz et al. (2014). Propôs-se que todas as estações deveriam produzir de acordo com o tempo takt do setor, desenvolvendo um fluxo contínuo das carrocerias pelas estações da linha de pintura automotiva, bem como, evitando a geração de excesso de produção.

REVISTA dE CIÊNCIA \& TECNOLOGIA • v. 20, N. 40, p. 21-45 • 2017• ISSN Impresso: 0103-8575•ISSN Eletrônico: ISSN: 2238-1252 
Para desenvolver o mapa de fluxo de valor futuro, foi preciso trabalhar nos pontos de melhoria identificados no mapa de fluxo de valor do estado atual. Com a otimização da estação de Inspeção 1, alguns desses pontos puderam ser solucionados. A partir da redução do tempo de ciclo da estação para 6,9 min./unidade (Figura 8), a estação de Inspeção 1 passa a trabalhar de acordo com o tempo takt do setor de pintura, o que eliminaria os estoques acumulados nas estações anteriores (Limpeza e Estufa 2) em 10 unidades, gerando uma redução de 70 min. no tempo de carrocerias em processo. Outro ponto de melhoria alcançado com a otimização da estação de Inspeção 1 é o aumento da disponibilidade das estações de Limpeza e Estufa 2, nas quais, como estas não ficariam mais paradas devido ao acúmulo de estoques na linha pela estação de Inspeção 1, as horas de parada de produção seriam eliminadas, elevando a disponibilidade das estações para 95\% e 100\% respectivamente.

Com o objetivo de seguir a regra de que todas as estações devem trabalhar de acordo com o tempo takt do setor, as estações de Selante 1 e Selante 2, identificadas como estações críticas pelo mapa de fluxo de valor atual (Figura 6), precisariam ter seus tempos de ciclo reduzidos. Assim, foram levantadas as seguintes propostas de melhoria que resultariam na redução do tempo de ciclo dessas estações:

- Para a estação de Selante 1, propõe-se um estudo de tempos e métodos na estação, bem como, um balanceamento de operações entre os operadores, de forma que todos fiquem com a mesma carga de trabalho e consigam reduzir o tempo de ciclo da estação.

- Nas estações de Selante 1 e Selante 2, sugere-se uma adaptação no layout da estação, com a intenção de colocar as pistolas de aplicação de selante e os materiais utilizados no acabamento mais perto do operador, eliminando a movimentação desnecessária na busca por esses itens.

- Na estação de Selante 2, sugere-se a aplicação do estudo de tempos e métodos e a divisão correta das operações entre os três operadores, em que cada um ficaria responsável por uma área específica da carroceria, na qual deve ser aplicado selante, fazendo que não haja uma dependência entre eles e não ocorra o cruzamento no momento da movimentação; também nessa estação sugere-se um aumento de até 30\% da velocidade de elevação do carro, para aumentar a produtividade sem prejudicar ou expor os operadores a riscos de acidente.

- Sugere-se também a implantação de mecanismos de gestão visual incentivando os operadores a produzirem dentro ou o mais próximo possível do tempo takt.

Para o desenho do mapa de fluxo de valor futuro, procurou-se manter os estoques presentes no início e no final da linha de pintura automotiva, pois, segundo Howard (2000), esses estoques servem para alcançar o melhor mix de produtos no setor de montagem por meio do re-sequenciamento das carrocerias pintadas de diferentes cores e modelos, bem como ter um estoque adicional caso seja necessário substituir alguma carroceria danificada, fazendo que não haja interrupção no fluxo produtivo enquanto a carroceria danificada é reparada. Com esse cenário, desenhou-se o mapa de fluxo de valor futuro proposto para a carroceria Modelo Y (Figura 8). 


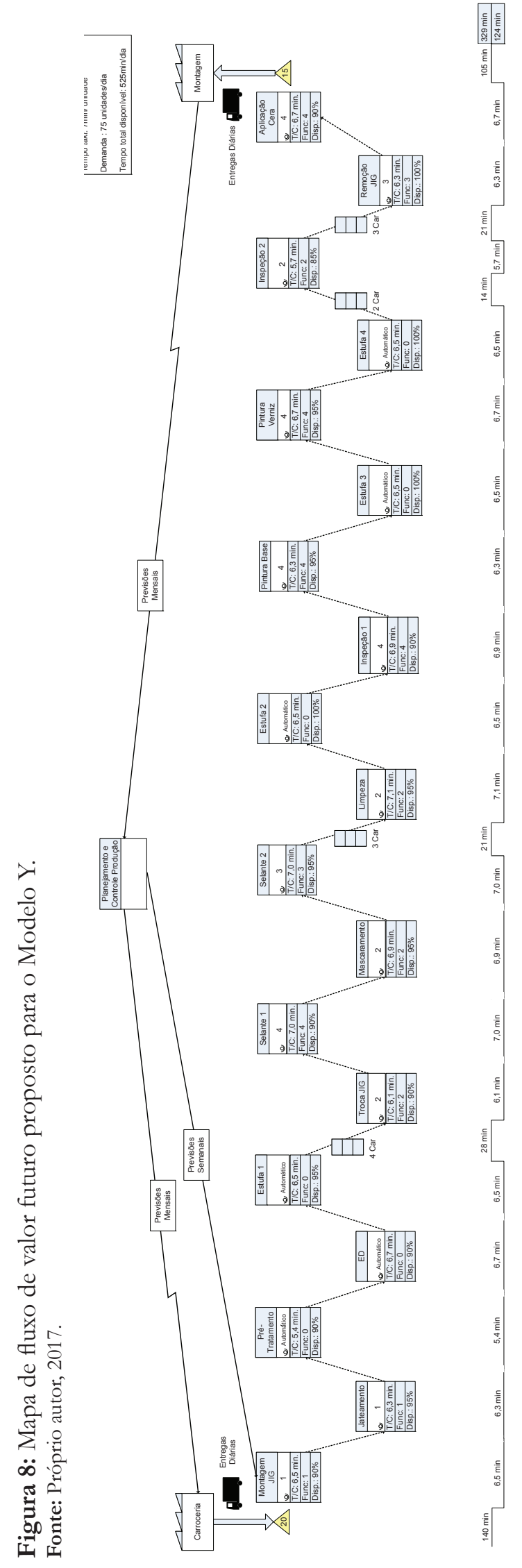




\subsubsection{Comparação da situação atual e futura}

De acordo com a Figura 8, o processo de produção da carroceria Modelo Y no setor de pintura passa a ter um tempo de processamento de 124 minutos ( 2 horas e 3 min.), o qual reduziu em 10 min., quando comparado com a situação atual da linha de pintura automotiva, devido ao fato de os tempos de ciclo das estações de Selante 1, Selante 2 e Inspeção 1 terem sido reduzidos e adequados ao tempo takt do setor. Outro ponto a ser observado é que o tempo das carrocerias que ficam em estoque entre processos passou a ser de $329 \mathrm{~min}$. (5 horas e $28 \mathrm{~min}$.), resultado da otimização feita na estação de Inspeção 1 e nas propostas levantadas para a redução do tempo de ciclo das estações de Selante 1 e Selante 2, o que levou à redução de estoques desnecessários entre processos. Ao ser somado o tempo de processamento com o tempo de carrocerias que ficam em estoques entre processos, obtém-se um lead time de $453 \mathrm{~min}$. (7 horas e 33 min.), o que coloca o processo de pintura da empresa estudada dentro do tempo normal (8 horas) de produção de uma linha de pintura automotiva, segundo Svejda (2012).

Observa-se, na Tabela 5, que haverá uma redução no lead time total de $26 \%$, o que possibilita ao setor de pintura automotiva entregar carrocerias pintadas com maior rapidez para o processo de montagem. Já em relação aos estoques intermediários de processo, por meio das otimizações de todas as estações mais críticas, haverá uma redução de $31 \%$ no número de carrocerias entre processos. Para a disponibilidade do processo, pode-se perceber um aumento de $5 \%$ quando comparado com o estado atual, uma vez que as disponibilidades das estações de Limpeza e Estufa 2 aumentaram com a otimização da estação de Inspeção 1. As diferenças percentuais que constam na Tabela 5 são significativas, o que indica que o processo atual se beneficiaria com as melhorias propostas nas estações de Selante 1 e Selante 2, bem como ao manter as melhorias aplicadas na estação de Inspeção 1.

Tabela 5: Comparação entre características da situação atual e futura.

\begin{tabular}{cccc}
\hline Características & Atual & Futura & Diferença (\%) \\
\hline $\begin{array}{c}\text { Disponibilidade média } \\
\text { do processo (\%) }\end{array}$ & $90 \%$ & $95 \%$ & $5 \%$ \\
\hline $\begin{array}{c}\text { Estoques intermediários } \\
\text { de processo (unid.) }\end{array}$ & 68 & 47 & $-31 \%$ \\
\hline Lead time (min.) & 609 & 453 & $-26 \%$ \\
\hline
\end{tabular}

Fonte: Próprio autor, 2017.

\section{CONSIDERAÇÕES FINAIS}

Considerando a complexidade do processo de pintura automotiva, este estudo buscou apresentar uma proposta de redução no lead time em uma linha de pintura, que pode mostrar desperdícios ao longo da cadeia produtiva e influenciar diretamente no lead time do processo. Com a elaboração do mapa de fluxo de valor atual desse processo para o modelo de carroceria 
de maior retorno financeiro para a organização e a obtenção do lead time atual da linha, pode-se observar desperdícios no decorrer do processo produtivo, uma vez que havia estações de trabalho com tempo de ciclo acima do tempo takt e estoques em processo.

Uma vez selecionada a estação mais crítica da linha (Inspeção 1), aplicou-se nessas melhorias que resultaram em uma sequência de trabalho definida para todos os operadores dentro do tempo takt do setor. Como resultado, reduziu-se o tempo de ciclo desta e possibilitou um aumento na disponibilidade das estações anteriores, bem como, a eliminação dos estoques formados pelo alto tempo de ciclo. Além disso, identificaram-se propostas de melhorias para as demais estações críticas do processo (Selante 1 e Selante 2), as quais fizeram parte do mapeamento de fluxo de valor futuro.

Como resultado, obteve-se uma redução de $26 \%$ no lead time total da linha de pintura, bem como, uma redução de 31\% nos estoques entre processos (WIP) e um aumento de 5\% na disponibilidade média da linha. Tais resultados auxiliam a linha de pintura a operar dentro do tempo takt projetado pela empresa.

Como limitações, pode-se destacar a dificuldade de comunicação com todos os envolvidos na equipe de trabalho no momento da elaboração do MFV atual e futuro, assim como, da elaboração e aplicação das melhorias no processo produtivo, uma vez que, nessa equipe, estavam inclusos supervisores de linha, o gerente da produção e os operadores líderes do processo.

Para contribuições futuras, sugere-se a aplicação e validação das melhorias propostas nas estações de Selante 1 e Selante 2. Recomenda-se também a realização de um estudo de tempos, métodos e movimentações nas demais estações da linha de pintura, de forma a identificar os desperdícios relacionados com a execução das operações, com a movimentação dos operadores e com o layout das estações de trabalho.

\section{REFERÊNCIAS}

BARRETO, A. R. Sistema Toyota de Produção: Lean Manufacturing Implantação e Aplicação em uma Indústria de Peças Automotivas. Tékhne e Lógos, São Paulo, v. 3, n. 2, 2012. Disponível em: < http://www.fatecbt.edu.br/seer/index.php/tl/article/viewFile/54/118>. Acesso em: 10 mar. 2016.

BATISTA G. R., et al. Análise do Processo Produtivo: Um estudo Comparativo dos Recursos Esquemáticos. In: ENCONTRO NACIONAL DE ENGENHARIA DE PRODUÇÃO, 26, 2006, Fortaleza. Anais Eletrônicos. Disponível em: http://abepro.org.br/biblioteca/ENEGEP2006 TR450307 7954.pdf. Acesso em: 4 abr. 2016.

BODANA, K.; MAWANDIYA, B. K.; PATEL, K. M.; MODI, B. A. “An Application of Value Stream Mapping in Production Flow Analysis: A lean approach in An Automotive Industry." Nirma University Journal of Engineering and Technology, v. 5, n. 1, 2016.

CALSAVARA, N. A. "Application of the Lean Office philosophy and mapping of the value stream in the process of designing the banking units of a financial company." GEPROS: Gestão da Produção, v. 11, n. 3, 2016. 
CHANESKI, W. S. "Value-Stream Mapping Improves Admin Processes." Modern Machine Shop, v. 84, n. 11, 2012.

CHAVEZ, Z.; TAKEFUMI, M.; MICHIRU, U. “Divergence between Value Stream Mapping Western Understanding and Material and Information Flow Chart Principles: A Japanese Automotive Supplier's Perspective.” Journal of Service Science and Management, v. 11, n. 2, 2018.

DENNIS, P. Produção LEAN simplificada: um guia para entender o sistema de produção mais poderoso do mundo, 2. ed. Porto Alegre: Bookman, 2008.

FAULKNER, W.; FAZLEENA, B. "Sustainable Value Stream Mapping (Sus-VSM): methodology to visualize and assess manufacturing sustainability performance." Journal of Cleaner Production, v. 85, 2014.

GORI, R. M. O Balanceamento de Uma Linha de Montagem Seguindo a Abordagem Lean Manufacturing. In: ENCONTRO NACIONAL DE ENGENHARIA DE PRODUÇÃO, 32, 2012, Bento Gonçalves. Anais Eletrônicos. Disponível em: http://www.abepro.org.br/biblioteca/enegep2012 TN STO 157 919 19757.pdf. Acesso em: 4 abr. 2016.

HOWARD, M. Paint Shop Survey: a report on the current state of automotive painting and its impacts on customer order fulfilment. In: UNIVERSITY OF BATH, 1, 2000, Inglaterra. Anais eletrônicos. Disponível em: http://www.3daycar.com/mainframe/publications/library/Paint.pdf. Acesso em: 17 mar. 2016.

KACH, S. C. et al. Mapeamento do Fluxo de Valor: Otimização do Processo Produtivo sob a ótica da Engenharia da Produção. In: SIMPÓSIO DE EXCELÊNCIA EM GESTÃO E TECNOLOGIA, 11, 2014, São Paulo. Anais eletrônicos. Disponível em: http://www.aedb. br/seget/arquivos/artigos14/20520470.pdf. Acesso em: 12 mar. 2016.

LIKER, J. K.; MEIER, D. O modelo Toyota: manual de aplicação: um guia prático para a implementação dos 4 PS da Toyota. Porto Alegre: Bookman, 2007.

MACHADO. F. P. Caracterização Físico-Quimica das Efluentes Líquidos Oriundos de Uma Oficina Automotiva: Estudo de Caso. In: UNIVERSIDADE TECNOLÓGICA FEDERAL DO PARANÁ, 2013. Anais Eletrônicos. Disponível em: http://repositorio.roca.utfpr.edu. br/ispui/bitstream/1/4629/1/MD GAMUNI 2014 2 86.pdf . Acesso em 9 mar. 2016.

MESQUITA, D. C. V. et al. Implementação do Mapeamento do Fluxo de Valor de uma Montadora de Veículos, Denominada Empresa Beta. Exacta, São Paulo, v. 12, n. 2, 2014. Disponível em: < http://www.redalyc.org/pdf/810/81032895005.pdf>. Acesso em: 11 mar. 2016. MIGUEL, P. A. C. Estudo de caso na engenharia de produção: estruturação e recomendações para sua condução. Produção, São Paulo, v. 17, n. 1, 2007. Disponível em: http://www.scielo. br/pdf/prod/v17n1/14.pdf. Acesso em: 23 jun. 2017.

MIGUEL, P. A. C. et al. Metodologia de Pesquisa em Engenharia de Produção e Gestão de Operações. Rio de Janeiro: Elsevier, 2011. 
MUCHFIRODIN, M.; HENRY, Y.; ADI, J. G. “The Improvement of Sugar Distribution System Using Value Stream Mapping (VSM) Approach A Case Study: Industri Gula Nusantara, Kendal, Jawa Tengah.” Agritech, v. 33, n. 1, 2013.

QUEIROZ, J. A. et al. Transformação Enxuta: Aplicação do Mapeamento do Fluxo de Valor em uma Situação Real. In: ENCOTNRO NACIONAL DE ENGENHARIA DE PRODUÇÃO, 24, 2004, Florianópolis. Anais eletrônicos. Disponível em: http://www.abepro.org.br/ biblioteca/ENEGEP2004 Enegep0101 0361.pdf. Acesso em: 12 mar. 2016.

RIBEIRO, H. P. A Competitividade da Industria Automobilística Brasileira. In: ASSOCIAÇÃO NACIONAL DE PÓS-GRADUAÇÃO E PESQUISA EM ADMINISTRAÇÃO, 13, 2010, Rio de Janeiro. Anais Eletrônicos. Disponível em: http://www.anpad.org.br/diversos/ trabalhos/EnANPAD/enanpad 2000/ADE/2000 ADE195.pdf. Acesso em: 8 mar. 2016.

ROTHER, M.; SHOOK, J. Aprendendo a enxergar: mapeando o fluxo de valor para agregar valor e eliminar o desperdício. São Paulo: Lean Institute Brasil, 2003.

STREITBERGER, H. J.; DÖSSEL, K. F. Automotive Paints and Coatings, 2. ed. Weinheim: Wiley-VCH, 2008.

SVEJDA, P. Pintura de Automóveis na China, Totalmente Automática e Eficiente. Brasil Engenharia, 21 dez. 2012. Disponível em: http://www.brasilengenharia.com/portal/images/ stories/revistas/edicao612/art_producao 612.pdf. Acesso em: 9 mar. 2016.

TAPPING, D. et al. Value Stream Management: eight steps to planning, mapping, and sustaining lean improvements. Productivity Press. New York, 2002. Anais Eletrônicos. Disponível em: < http://www.upv.es/i.grup/repositorio/Tappingoffice.pdf>. Acesso em: 5 abr. 2016.

TREVIZAN, J. G. Melhoria Continua da Qualidade no Processo de Pintura Automotiva. Produto \& Produção, 13 nov. 2013. Disponível em: http://www.lume.ufrgs.br/bitstream/handle/10183/97351/000920104.pdf?sequence=1 Acesso em: 29 fev. 2016.

TYAGI, S.; CHOUDHARY, A. K.; CAI, X.; KAI, Y. "Value stream mapping to reduce the lead-time of a product development process." International Journal of Production Economics, v. 160, 2015.

Submetido em: 23-6-2017

Aceito em: 20-6-2018 


\section{APÊNDICE A - FICHAS DE CRONOANÁLISE DOS OPERADORES DA ESTAÇÃO DE INSPEÇÃO 1}

\section{Ficha 1: Operador Lado Direito}

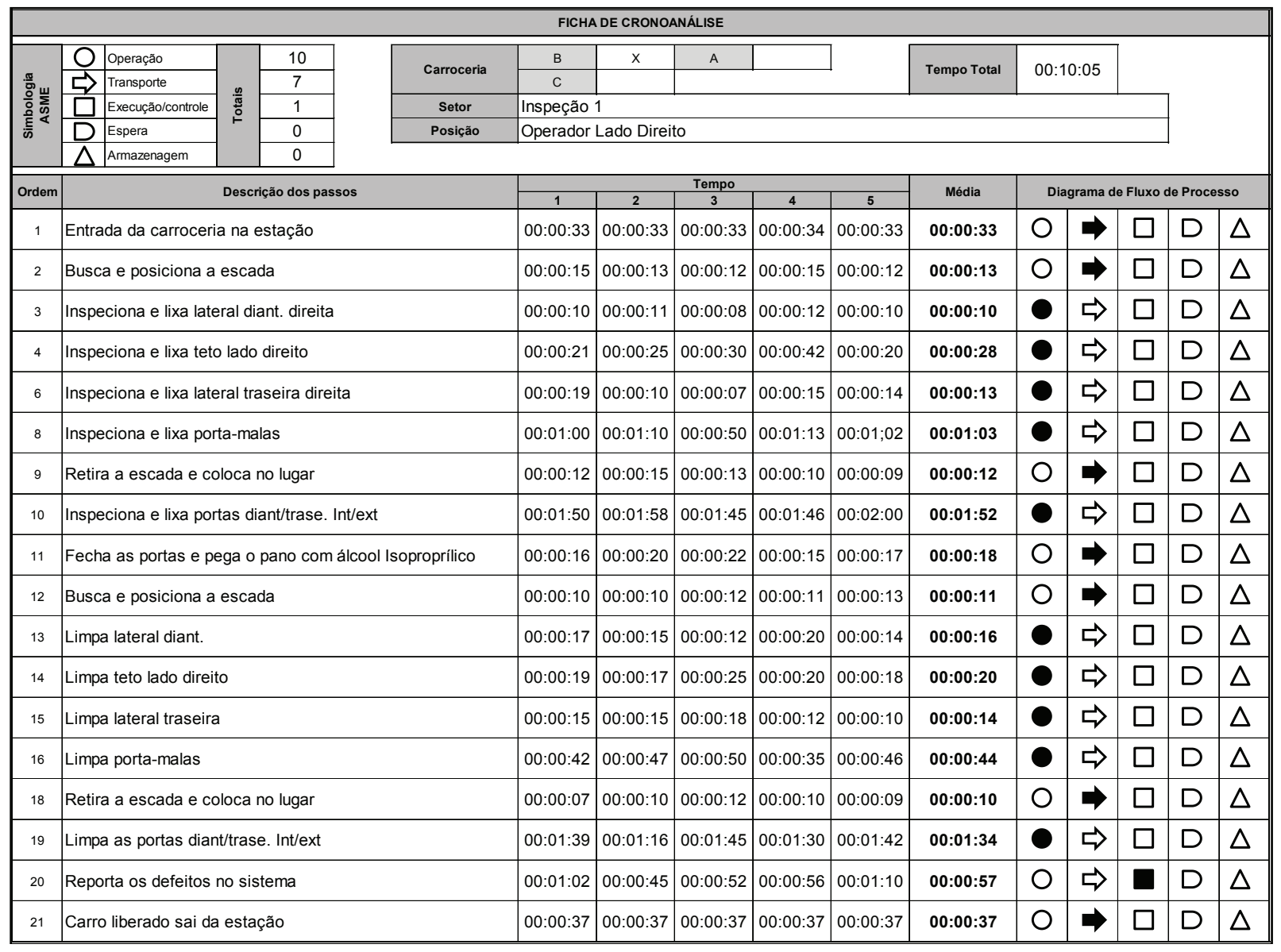




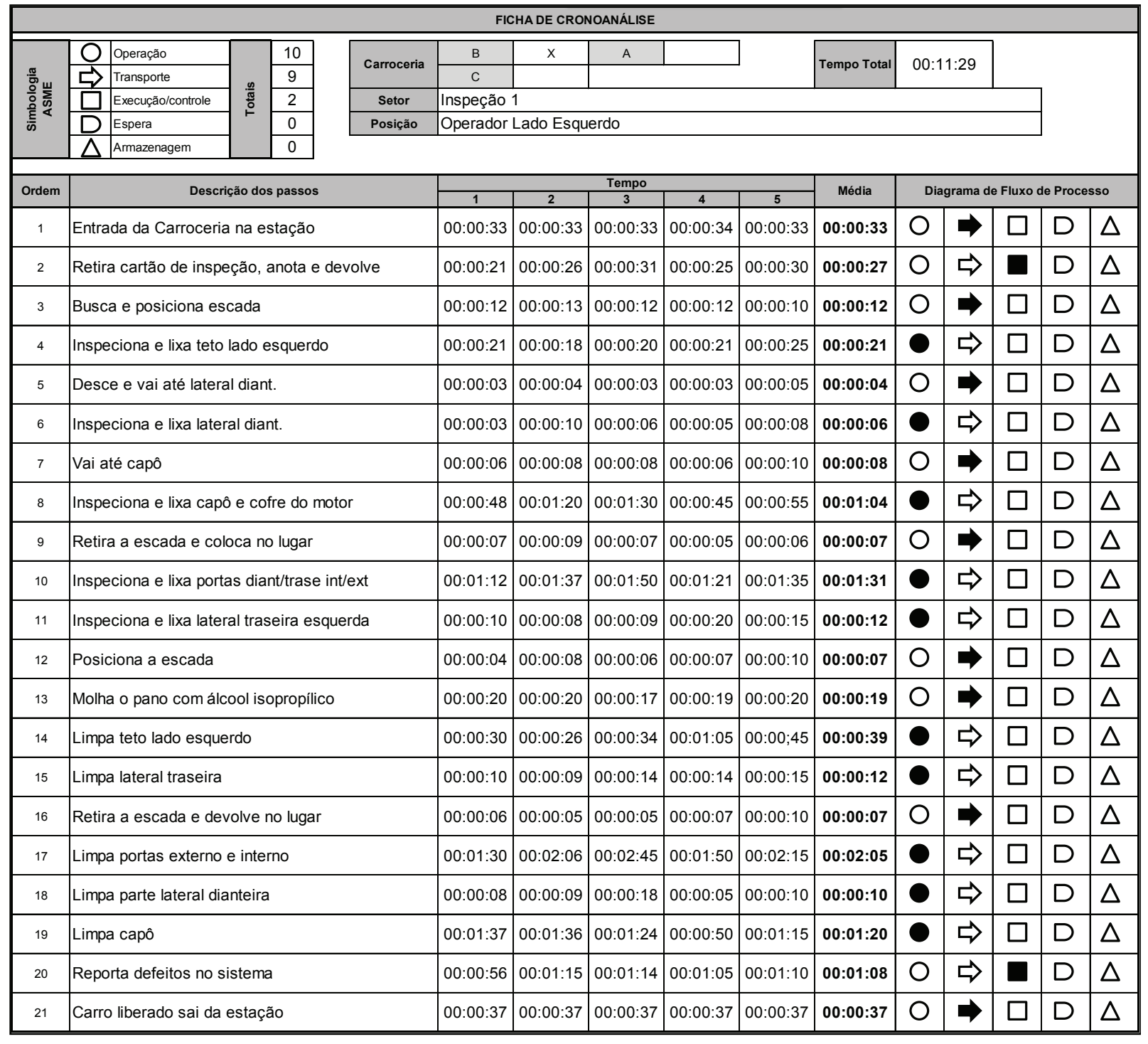


APÊNDICE B - FICHAS DE CRONOANÁLISE DOS OPERADORES DA ESTAÇÃO DE INSPEÇÃO 1, APÓS MELHORIAS E BALANCEAMENTO DE OPERAÇÕES

Ficha 1: Operador Lado Direito

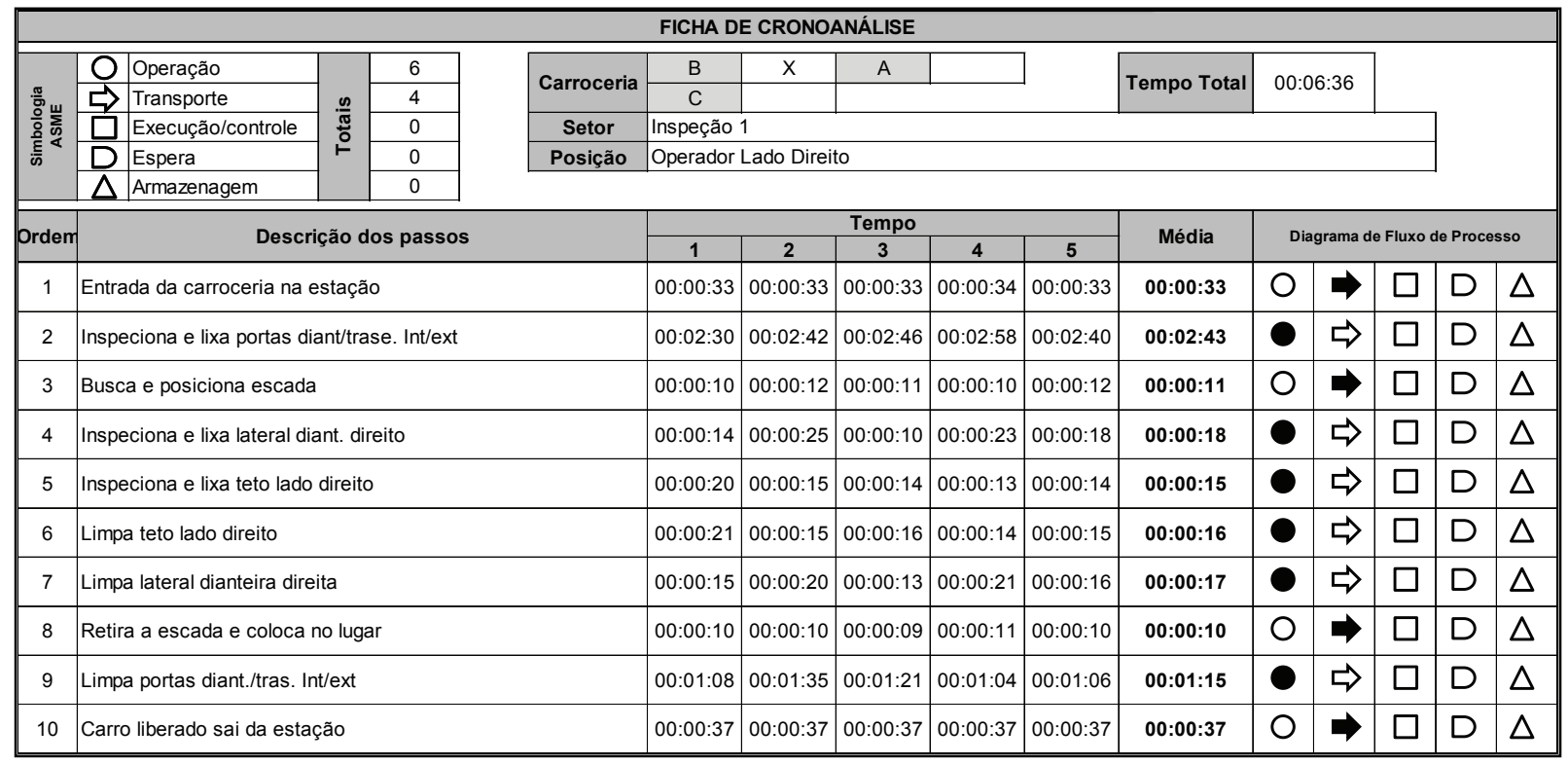

\section{Ficha 2: Operador Lado Esquerdo}

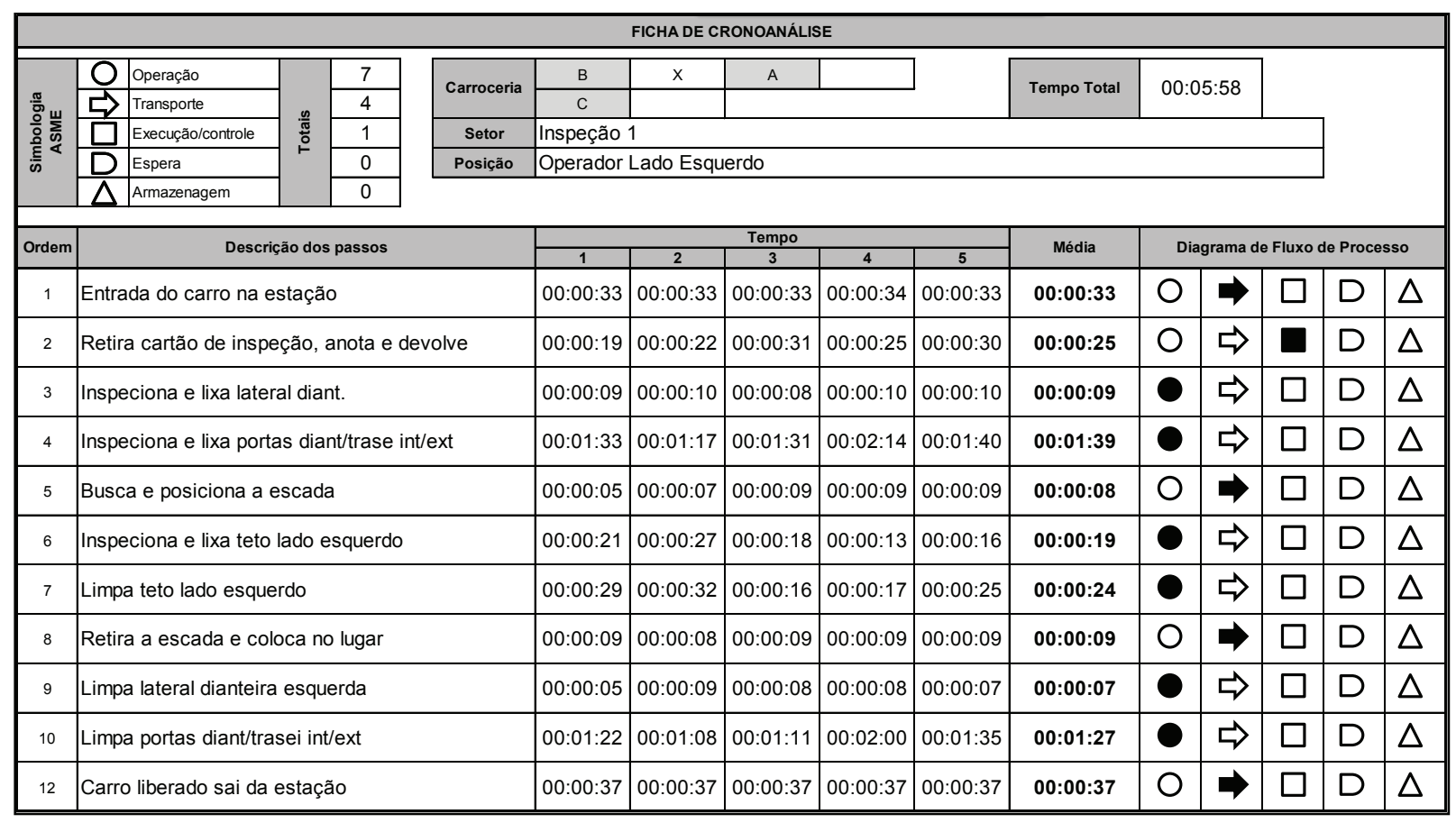

